\title{
SOSIALISASI PENGGUNAAN INTERNET SEHAT BAGI REMAJA KARANG TARUNA
}

\author{
Agus darmawan $^{1}$, Mei Lestari ${ }^{2}$, Yuni Wibawati $^{3}$ \\ Informatika, Fakultas Teknik dan Ilmu Komputer \\ Universitas Indraprasta PGRI
}

\begin{abstract}
Abstrak
Internet merupakan jaringan komunikasi dan informasi global. Hadirnya internet didunia memberikan pengaruh yang luar biasa terhadap kehidupan manusia. Internet tidak bisa lepas dari sisi negatif dan positif. Perilaku menggunakan media informasi berbasis internet berkaitan erat dengan sedikit banyak materi negatif. Banyak remaja terjebak dalam penyalahgunaan internet yang tentunya ini menjadi ancaman tersendiri bagi generasi kita. Perlu adanya pemahaman tentang penggunaan Internet Sehat dalam kegiatan mendampingi remaja saat mengakses internet. Tim pengusul kegiatan pengabdian masyarakat mengusulkan untuk melakukan sosialisasi penggunaaan internet terhadap remaja secara sehat dan bijak serta sosialisasi penggunaan Aplikasi DSN Nawala untuk menyaring jenis konten negatif.
\end{abstract}

Kata kunci : Internet, Filtering dan Konten Negatif

\begin{abstract}
The internet is a global communication and information network. The presence of the internet in the world has a tremendous influence on human life. The internet cannot be separated from the negative and positive side. Behavior using internet-based information media is closely related to a little more negative material. Many teenagers are trapped in the abuse of the internet, which of course is a threat to our generation. There needs to be an understanding of Healthy Internet use in activities accompanying teenagers when accessing the internet. The team that proposes community service activities proposes to socialize the use of the internet to adolescents in a healthy and wise manner and to socialize the use of the Newsletter DSN Application to filter out the types of negative content.
\end{abstract}

Keywords: Internet, Filtering and Negative Content

Correspondence author: Name, Agus Darmawan, kustiannunu@gmail.com, Indonesia

This work is licensed under a CC-BY-NC

\section{PENDAHULUAN}

Internet merupakan jaringan komunikasi dan informasi global. Banyak manfaat bisa didapat hanya bermodalkan kemampuan dan kemauan menggunakan internet, seperti berkorespodensi dengan mudah, murah, dan cepat keseluruh penjuru dunia. Internet merupakan salah satu media informasi yang kapan saja dan apa saja bisa diakses. 
Hadirnya internet didunia memberikan pengaruh yang luar biasa terhadap kehidupan manusia. Berbagai kemudahan yang dapat diperoleh dari internet, menjadi alasan pengguna internet setiap tahun mengalami peningkatan secara signifikan. Pada tahun 2015 tercatat lebih dari 3,15 miliar pengguna aktif diseluruh dunia. Pengguna internet di Indonesia setiap tahun juga mengalami peningkatan yang signifikan.

Internet tidak bisa lepas dari sisi negatif dan positif. Perilaku menggunakan media informasi berbasis internet berkaitan erat dengan sedikit banyak materi negatif. Semakin waspada dan tidak ceroboh dalam menggunakan internet, maka akan memperkecil kemungkinan terpengaruh berbagai materi negatif dari internet. Untuk itu diperlukan penggunaan internet secara sehat.

Internet sehat adalah segala sesuatu yang berkaitan dengan aktifitas menggunakan internet yang memiliki nilai positif bagi pengguna dan bagi orang lain. Internet sehat merupakan upaya atau ajakan kepada masyarakat pengguna internet untuk memanfaatkan internet untuk hal-hal yang positif.

Maraknya penyalahgunaan internet untuk mengakses situs-situs pornografi menjadi hal yang sangat memprihatinkan. Hal ini bisa jadi disebabkan karena kurangnya kontrol dari orang tua terhadap remaja saat remaja mengakses internet. Atau penyebab lain adalah karena belum terbentuknya kesadaran dalam diri remaja untuk menggunakan internet secara bijak.

Untuk menghindari permasalahan di atas, hendaknya orang tua terus menanamkan kesadaran dalam diri anak berkaitan dengan penggunaan internet yang sehat. Selain itu orang tua hendaknya juga mendampingi anak saat anak mengakses internet. Hal ini mengingat tidak ada filter atau penyaringan informasi dari internet.

Namun, jika orang tua memiliki kendala untuk mendampingi remaja saat remaja mengakses internet, maka hal hal yang dapat dilakukan adalah dengan memberi filter pada internet yang digunakan. Dengan kata lain menyediakan internet yang sehat dengan disertai upaya penerapan kesadaran berinternet yang sehat terhadap anak. Sebenarnya banyak cara yang dapat dilakukan, baik yang berbayar atau yang gratis.

DNS Nawala adalah sebuah layanan DNS Filter yang bebas digunakan oleh pengguna internet yang membutuhkan saringan situs internet negatif. DNS Nawala membantu pengguna internet menyaring jenis konten negatif yang tidak sesuai dengan peraturan perundangan, nilai dan norma sosial, adat istiadat dan kesusilaan bangsa Indonesia seperti situs situs yang berisi konten pornografi dan perjudian.

Selain kedua jenis situs negatif di atas, DSN Nawala juga akan menyaring situs Internet yang mengandung konten berbahaya seperti malware, situs phising (penyesatan) dan sejenisnya. Layanan DSN Nawala sepenuhnya gratis, DSN Nawala dibiayai dari donasi yang diberikan oleh pihak-pihak yang peduli tentang pentingnya Internet yang bersih dan aman. DSN Nawala dapat digunakan pada berbagai Sistem Operasi, bahkan di perangkat bergerak atau ponsel tertentu juga dapat dimanfaatkan (http://www.nawala.id/)

Berdasarkan permasalahan yang diangkat tersebut maka perlu ada Sosialisasi layanan DNS Filter yang merupakan salah satu picture sebuah aplikasi DSN Nawala. Nawala dapat membantu pengguna internet menyaring jenis konten negatif yang tidak sesuai dengan peraturan perundangan, nilai dan norma sosial, adat istiadat dan kesusilaan bangsa Indonesia seperti situs situs yang berisi konten pornografi dan perjudian di Karang Taruna dan Karang Taruna 


\section{METODE PELAKSANAAN}

\section{Khalayak Sasaran Kegiatan}

Sasaran kegiatan pengabdian ini adalah pengurus dan anggota Karang Taruna Zona 302 RW 02 Kelurahan Curug, Cimanggis, Depok dan Karang Taruna RT 005 RW 010 Kelurahan Lubang Buaya, Cipayung Jakarta Timur. Diharapkan dengan diberikan pelatihan Pemanfaatan aplikasi DSN Nawala pengurus dan anggota karang taruna dapat untuk menciptakan Internet Sehat bagi.

\section{Metode Pelaksanaan}

Metode yang digunakan dalam pengabdian masyarakat ini adalah metode seminar. Metode Seminar adalah suatu kegiatan ilmiah yang dilaksanakan oleh beberapa orang dalam suatu sidang yang berusaha membahas/mengupas masalah-masalah atau hal-hal tertentu dalam rangka mencari jalan memecahkannya atau pedoman pelaksanaannya.

Dengan situasi dan kondisi yang ada dalam karang taruna, maka kami menawarkan solusi untuk melakukan tinjauan dan melakukan workshop langsung terhadap para pengurus dan anggota karang taruna untuk lebih memahami pemanfaatan aplikasi DSN Nawala untuk menciptakan Internet Sehat.

\section{Langkah Kerja Metode}

Metode langkah kerja dalam pelaksanaan program pengabdian masyarakat ini adalah sebagai berikut:

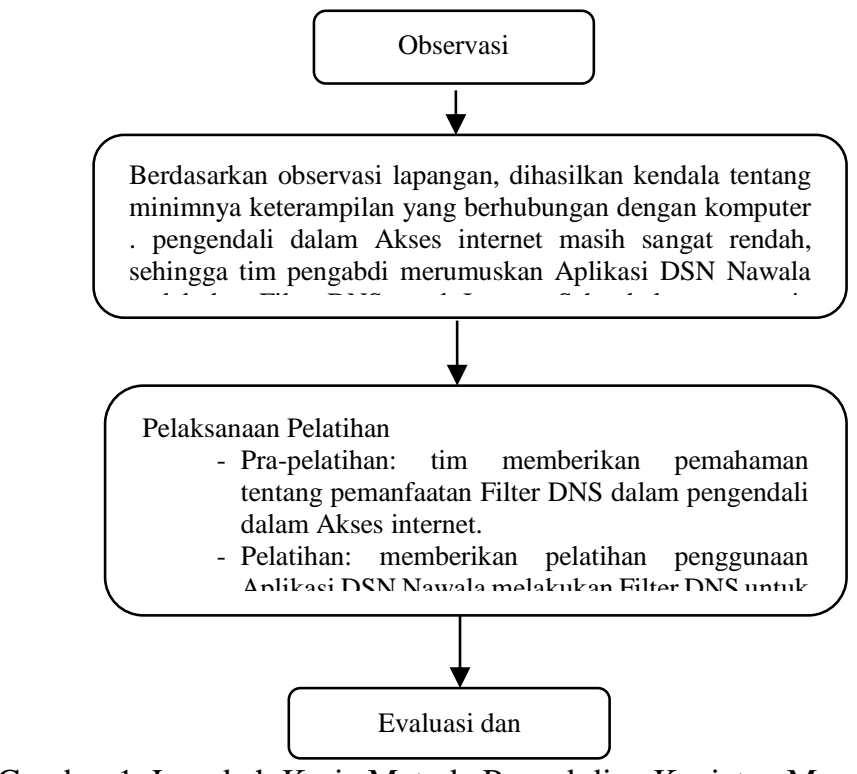

Gambar 1. Langkah Kerja Metode Pengabdian Kegiatan Masyarakat

\section{Bahan dan Alat yang Digunakan} berikut:

Bahan dan alat yang digunakan dalam program pengbdian ini adalah sebagai

1. Modul dengan topik "pemanfaatan aplikasi DSN Nawala untuk menciptakan Internet Sehat".

2. Proyektor.

3. Laptop/Smartphone.

4. Internet. 


\section{HASIL DAN PEMBAHASAN}

Tim pengabdian masyarakat memberikan materi tentang Filter DNS Nawala yang sekarang sudah dimanfaatkan sebagai Internet sehat. Yang terjadi selama ini mitra masih terbatas dalam mengontrol akses internet padahal internet nerupakan sarana belajar baik dan cepat jika di gunakan dengan benar. Ketidak tahun orang tua terhadap remaja akses internet membuat sebagian orang tua kawatir terhadapat remaja akses internet, Sehingga butuh sebuah sarana yang mampu memaksimalkan kegiatan sosialisasi pengenalan internet sehat dan mampu menghilangkan waswas orang tua terhadap remaja .

Tim memberikan modul tentang aplikasi Filter DNS Nawala dan langkah-langkah filter DNS menggunakan aplikasi tersebut.

DNS Nawala adalah layanan gratis yang berupa filtering/penyaringan DNS yang bebas biaya dan dapat digunakan oleh semua pengguna internet. Layanan ini memfilter atau menyaring konten negatif berupa konten porno, kekerasan atau kejahatan internet. Layanan ini ditujukan untuk membantu para pengguna internet untuk menyaring konten yang tidak sesuai dengan perundangan, adat istiadat, nilai, norma sosial dan kesusilaan bangsa. Yang termasuk konten ini adalah konten pornografi, perjudian dan penipuan yang sudah sangat umum di dunia maya. Hal ini juga memberikan perlindungan bagi pengguna internet dari malwaer dan situs phising.

Kelebihan lain dari DNS nawala adalah:

1. Sifatnya gratis dan tidak dikenakan biaya apapun untuk menggunakan DNS filtering ini. Siapapun dan dimanapun boleh menggunakan DNS ini karena dibiayai dari donasi oleh komunitas dan pihak yang peduli terhadap pentingnya internet yang bersih, aman, nyaman dan menyenangkan.

2. Dapat digunakan di berbagai sistem operasi tanpa melakukan pemasangan software tertentu. Bahkan saat ini dapat digunakan di perangkat bergerak seperti ponsel dan tablet.

Pemerintah, dalam hal ini Kementrian Komunikasi dan Informatika sangat mendukung dan menyambut baik hadirnya DNS Nawala. Pemerintah memang sudah berusaha bertindak tegas terhadap konten pornografi di internet. Disebutkan bahwa pemblokiran konten pornografi ini sudah memiliki payung hukun yang cukup kuat yakni: 1. Undang-Undang No 44/2008 tentang Pornografi,

2. UU ITE Nomor 11 Tahun 2008 UU, dan

3. UU Telekomunikasi Nomor 36 Tahun 1999.

Saat ini pemerintah dan penyedia jasa internet (PJI) sudah menggunakan database dari Massive Trust Positif dan DNS Nawala untuk memblokir situs yang tidak sesuai, baik secara lokal maupun global. Dengan layanan ini diharapkan para pengguna internet, terutama orang tua dan orang yang peduli dengan moral bangsa dapat mengakses internet dengan nyaman dan tenang. Masyarakat dapat berpartisipasi dalam melaporkan situs porno dan situs lain yang tidak sesuai melalui situs nawala.org. 


\section{Tampilan Aplikasi DNS Nawala}

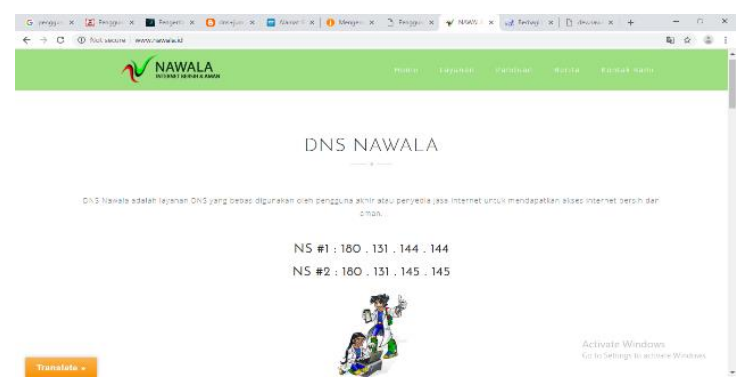

Gambar 2 Tampilan situs Aplikasi DNS NAWALA

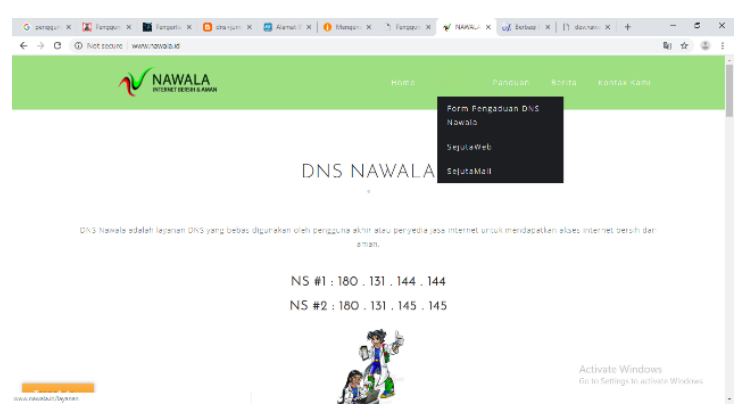

Gambar 3 Layanan Yang tersedia

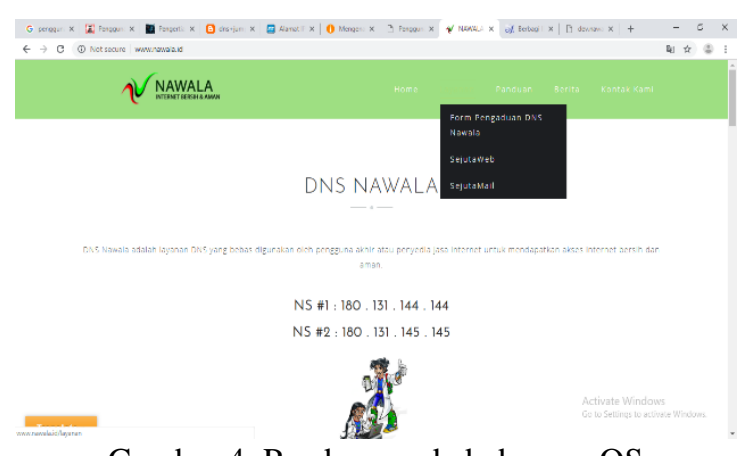

Gambar 4. Panduan pada beberapa OS

\section{Cara Penggunaan Cara Konfigurasi Aplikasi DNS Nawala untuk Sosialisasi Kegiatan}

\section{DNS Umum}

Untuk mengkonfigurasikan DNS Nawala ke sistem bisa dengan berbagai cara. Secara manual, kita hanya perlu mengubah setting IPv4 pada koneksi aktif yang kita gunakan. Caranya :

1. Buka Control Panel

2. Klik Network and Internet Nework and Sharing Center.

3. Pada tab sebelah kiri, klik Change adapter settings.

4. Pilih koneksi aktif yang kita gunakan, misalkan disini saya menggunakan Mobile Broadband Connection. Klik kanan kemudian pilih Properties.

5. Klik secara berurutan, Internet Protocol Version $4(\mathrm{TCP} / \mathrm{IPv} 4)>$ Properties.

6. Pada jendela Properties, pilih Use the following DNS server addressess: > Advanced.

7. Pada jendela TCP/IP settings, pilih tab DNS > Add.

8. Isikan DNS Nawala dan atau DNS Speedy. 
9. setting dns nawala dan dns speedy secara manual

\section{DNSCrypt}

DNSCrypt merupakan suatu aplikasi open source yang berfungsi untuk mengenkripsi koneksi antara user dengan server DNS yang dituju. Jadi kita bisa menggunakan fitur DNS dengan tunjangan sekuritas yang lebih baik dari ancaman spoofing, online spy, dll. Berikut merupakan panduan cara penggunaannya di platform Windows:

1. Download DNSCrypt .

Note: Ubah nama file yang anda unduh dari dnscrypt.anu menjadi dnscrypt.zip, dan setujui pertanyaan verifikasi ubah nama

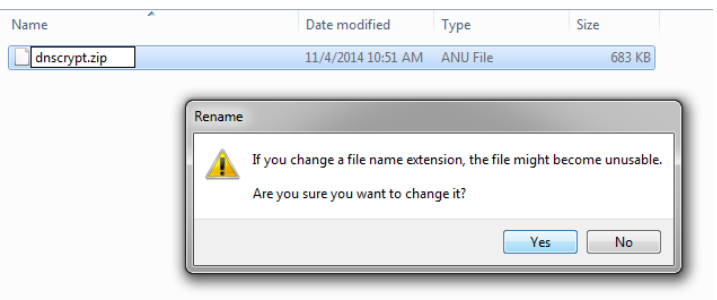

Gambar 5. pertanyaan verifikasi

2. Setelah rename, extract file dnscrypt.zip lalu masuk ke dalam folder bin dan jalankan file dnscrypt.bat

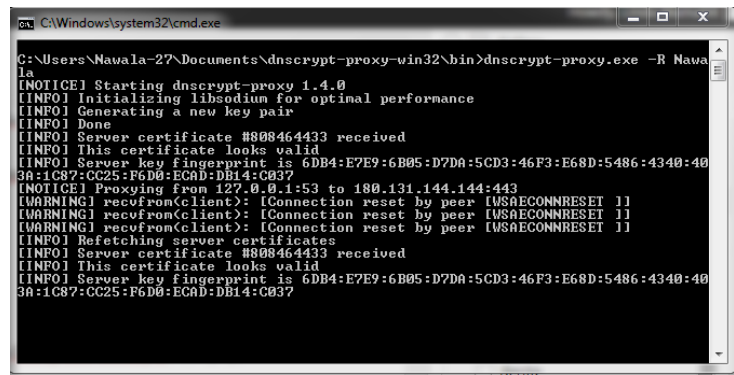

Gambar 5. jalankan file dnscrypt.bat

3. Masuk ke pengaturan DNS pada koneksi yang anda gunakan di PC/Laptop anda dan ubah setting Preferred DNS menjadi 127.0.0.1 seperti pada link berikut ini (Pengaturan DNS)

Untuk memeriksa apakah DNSCrypt bekerja, ikuti langkah-langkah sebagai berikut:

1. Masuk ke command prompt (dos prompt)

2. Jalankan perintah:

$>$ nslookup playboy.com 127.0.0.1

bandingkan dengan

$>$ nslookup playboy.com 8.8.8.8 


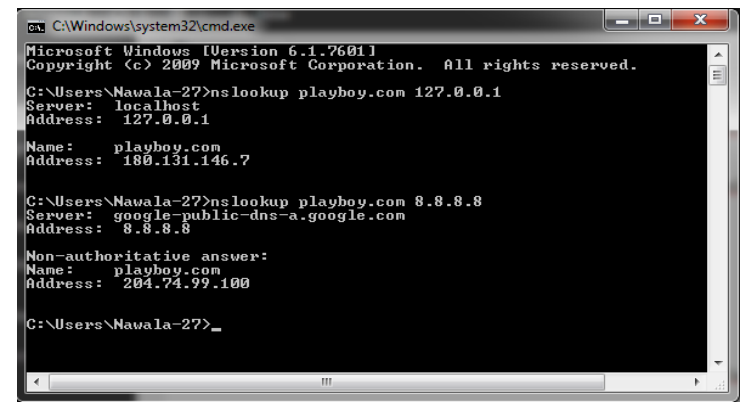

Gambar 6. dos prompt uji link

\section{Menggunakan DNS Jumper}

Penggunaan DNS jumper ini sudah pernah saya bahas pada bahasan sebelumnya mengenai setting DNS menggunakan DNS Jumper. Untuk dapat menggunakan DNS Nawala dan DNS Speedy dengan mudah melalui DNS Jumper, kita perlu memodifikasi file DnsJumper.ini yang terdapat pada folder DNS Jumper. Caranya :

1. Cari file DnsJumper.ini di folder DNS Jumper.

2. Buka file tersebut kemudian isikan DNS Nawala dan DNS Speedy dengan kode : ID - Nawala $=180.131 .144 .144,180.131 .145 .145$, True untuk Nawala, ID Speedy=203.130.196.6,222.124.204.34, True untuk Speedy.

3. Letakkan pada baris yang berbeda, pernyataan True mengindikasikan daftar tersebut sudah ter-centang secara default pada daftar Find Fastest DNS.

4. Simpan perubahan dan cek hasilnya dengan membuka DNS Jumper.

Dengan aplikasi Filter DNS Nawala yang sudah terinstal dilaptop masing-masing peserta pelatihan, dan dengan dipandu modul yang telah kami bagikan, maka kami memulai pelatihan. Dengan metode pelatihan satu pemateri menyampaikan di depan dengan mengunankan proyektor, sedangkan peserta pelatihan mengikuti materi dan praktik pada laptop masing-masing menggunakan panduan modul. Dalam prosesnya, 2 anggota tim melakukan fungsi error handling untuk mengatasi jika ada masalah ataupun pertanyaan dari peserta pelatihan.

\section{Pelaksana (21 November 2018 pukul: 08.00 s/d 10.00)}

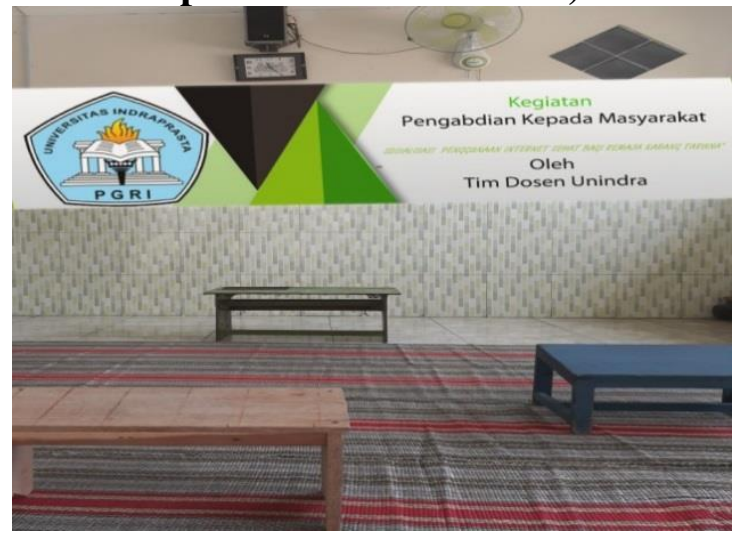

Gambar.7

Gambar.7 menggambarkan ketika tim memepersiapkan meja untuk para peserta yang ikit dalam sosialisasi tetang internet sehat. 


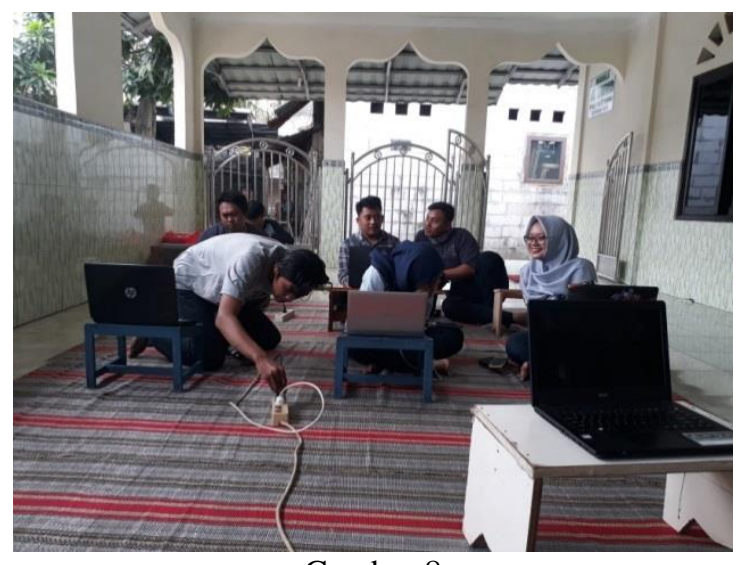

Gambar 8

Gambar.8. adalah kegiatan ketika perserta remaja melakukan persiapan serta tim abdimas melakukan pemantauan terhadap peserta pelatihan dalam mengikuti arahan proses, sebagai fungsi error handling dalam pelaksanaan pelatihan.

Gambar.9 tim sedang memeriksa hasil stop kontak untuk setiap latop berjalan dengan baik atau tidak.

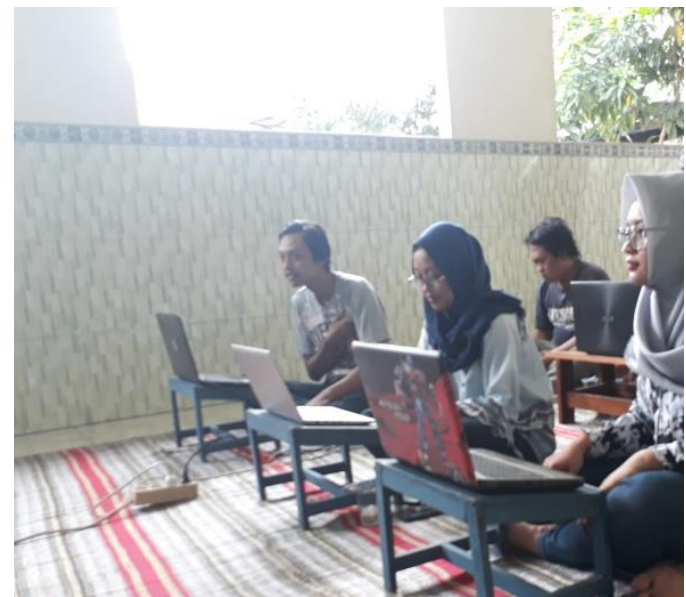

Gambar.10 Foto Bersama saat acara terlah acara sosialisan telah selesai .

Kegiatan pelatihan dilaksanakan pada tanggal 21 oktober 2018 dimuali pukul 08.00 wib s/d 10.00 wib dengan target peserta pelatihan sudah bias memgunakan internet yang sehat dengan menggunakan aplikasi Filter DNS Nawala ketika mereka pulang dari sosilisasi sehingga bisa digunakan untuk memaksimalkan upaya internet sehat.. 


\section{Pelaksana (28 Oktober 2018 pukul: 08.00 s/d 10.00)}

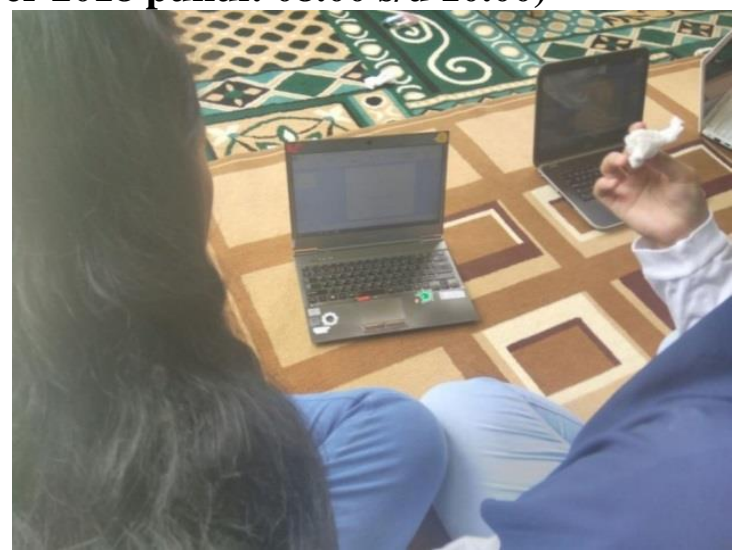

Gambar.1

Gambar.1 menggambarkan ketika tim memepersiapkan meja untuk para peserta yang ikit dalam sosialisasi tetang internet sehat.

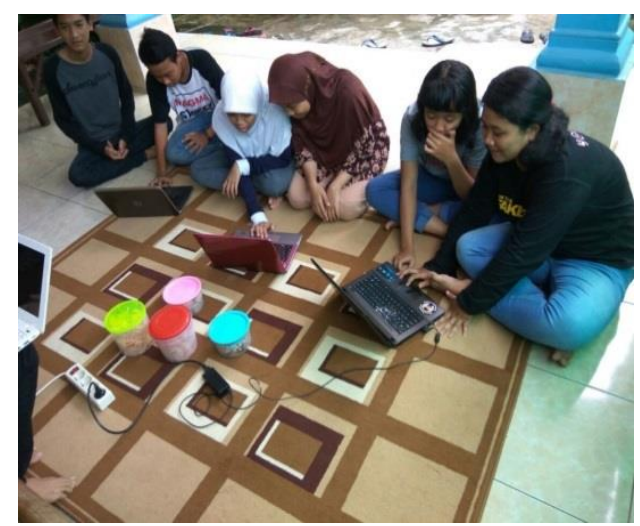

Gambar.2

Gambar.2 adalah kegiatan ketika perserta remaja melakukan persiapan serta tim abdimas melakukan pemantauan terhadap peserta pelatihan dalam mengikuti arahan proses, sebagai fungsi error handling dalam pelaksanaan pelatihan.

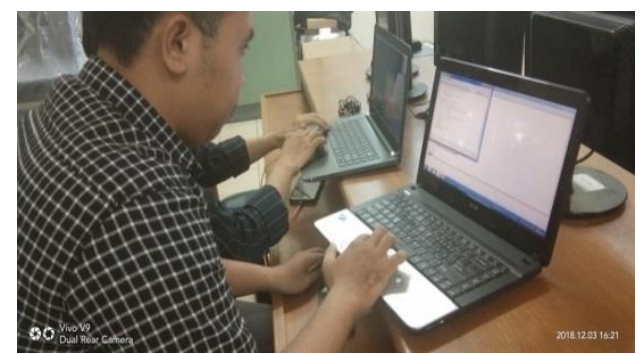

Gambar.3

Gambar.3 tim mahasiswa sedang mengatur dns Firter pada latop acara kegiatan abdimas 


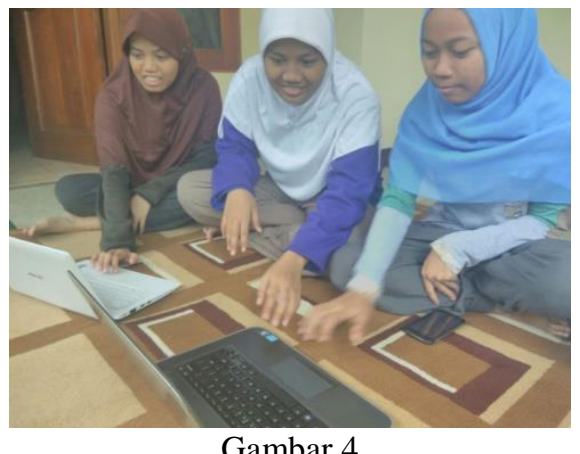

Gambar.4 Foto Bersama saat acara terlah acara sosialisan telah selesai .

Kegiatan pelatihan dilaksanakan pada tanggal 24 November 2015 dimuali pukul $08.00 \mathrm{wib}$ s/d 16.00 wib dengan target peserta pelatihan sudah bias memgunakan internet yang sehat dengan menggunakan aplikasi Filter DNS Nawala ketika mereka pulang dari sosilisasi sehingga bisa digunakan untuk memaksimalkan upaya internet sehat..

Secara umum kegiatan ini dapat dikatakan berhasil. Hal ini diindikasi dengan adanya tanggapan yang positif dari peserta dan lingkungan masyarakat setempat tentang adanya kegiatan ini. Hal ini juga ditunjukkan dari sikap ketua Rukun Warga (RW), ketua Rumah Tangga (RT), maupun pengurus karang taruna yang sangat mengharapkan kegiatan ini tidak hanya dilakukan sekali pada karang taruna namun dapat dilakukan secara rutin. Kegiatan ini juga melibatkan dua orang mahasiswa Universitas Indraparasta PGRI jurusan Informatika sebagai bantuan pelaksanaan kegiatan pengabdian masyarakat agar mahasiswa dapat mengikuti sosialisasi, memberikan pengarahan yang lebih baik kepada anggota maupun pengurus karang taruna yang mengikuti kegiatan sosialisasi ini dimana mereka lebih bisa menggunakan teknologi seperti komputer atau laptop dan sejenisnya, berlatih untuk bersosialisasi terhadap masyarakat sekitar agar bermanfaat kegunaannya sebagai mahasiswa serta lebih internet sehat yang dapat bermanfaat untuk diimplementasikan nanti ke dalam pola ke hidupan. Muncul harapan dari mahasiswa Universitas Indraprasta PGRI yang mengikuti sosialisasi ini untuk rutin dilibatkan dalam kegiatan pengabdian masyarakat selanjutnya.

\section{SIMPULAN}

Dari hasil pelatihan, diperoleh kesimpulan:

1. Mempermudah karang taruna untuk memahami dan mendalami materi yang diberikan dan berdampak positif pada peningkatan pengetahuan pengurus maupun anggota karang taruna.

2. Mendapatkan pelatihan pengoperasian aplikasi aplikasi DSN Nawala sehingga beberapa peserta sudah memaham internet sehat.

3. Menambah wawasan peserta dengan menggunakan komputer yang didukung oleh jaringan internet dan aplikasi aplikasi

4. DSN Nawala sebagai media filter dari situs- situs.

Adapun beberapa saran yang diajukan adalah sebagai berikut:

1. Kesiapan pengurus maupun anggota karang taruna dalam menghadapi segala kemajuan teknologi agar tidak menjadi kegagapan teknologi (gaptek) harus di tingkatkan . 
2. Kesediaan peralatan yang harus lebih memadai, terutama ketersediaan komputer yang kurang dan pengupdatean windows

\section{DAFTAR PUSTAKA}

Hidayanto, F. dan Ilmi, M. Z. (2015). Pentingnya Internet Sehat. Jurnal Inovasi dan Kewirausahaan, 4(1), 21-24.

Pibriana, D., \& Ricoida, D. I. (2017). Analisis Pengaruh Penggunaan Internet Terhadap Minat Belajar Mahasiswa (Studi Kasus: Perguruan Tinggi di Kota Palembang). JATISI (Jurnal Teknik Informatika dan Sistem Informasi), 3(2), 104115.

Purwanto, E., \& Marginingsih, M. (2014). Sistem Keamanan Akses Internet Sebagai Upaya Untuk Melindungi Remaja Terhadap Pornografi. Duta. Com, 7(1).

Sholeh, M. (2009). Analisis Pencegahan Akses Website Kategori Dilarang. Jurnal Teknologi, 2(2), 117-123. 